\title{
Efficiency assessment of Flash Profiling and Ranking Descriptive Analysis: a comparative study with star fruit-powdered flavored drink
}

\author{
Maria Eugênia de Oliveira MAMEDE ${ }^{1 *}$, Marta de Toledo BENASSI ${ }^{2}$
}

\begin{abstract}
The objective of this study was to assess the efficiency of Flash Profiling (FP) and Ranking Descriptive Analysis (RDA) methods regarding sensory characterization using star fruit-flavored drink as matrix. Sample A was used as a standard. Other three samples were prepared based on sample A, by adding sugar, citric acid, carboxymethylcellulose or dye. The same panel (twelve assessors) was used to carry out FP and, subsequently, RDA analysis. The qualitative training stage used in RDA method showed no difference regarding the assessors' performance and panel consensus compared to FP. Both methods were efficient and discriminated samples in a similar way and in agreement with the physicochemical characterization. However, astringent and bitter aftertaste attributes were additionally used in sample description by RDA. The latter attribute was also relevant for samples discrimination in RDA. FP application was simpler and faster, mainly regarding time spent by the assessors; however, RDA provided more comprehensive description of samples.
\end{abstract}

Keywords: sensory characterization; tropical fruit; discrimination; ranking procedure; descriptive analysis.

Practical Application: Alternative descriptive sensory methods allow outstanding characterization.

\section{Introduction}

Descriptive sensory techniques represent sophisticated tools for the sensory scientist and they are generally useful for a detailed specification of sensory attributes or when a comparison of sensory differences among several products is desired. Depending on the specific technique used, the description can be more or less objective, as well as qualitative or quantitative (Lawless \& Heymann, 2010). Traditionally, Flavor Profile (Cairncross \& Sjöstrom, 1950), the Texture Profile (Brandt et al., 1963), Quantitative Descriptive Analysis - QDA ${ }^{\mathrm{TM}}$ (Stone et al., 1974), Spectrum $^{\mathrm{TM}}$ methods (Munoz \& Civille, 1992) and Quantitative Flavor Profiling (Stampanoni, 1993) are mentioned as examples of descriptive analyses.

Literature on these traditional methods provides good quality data on the efficiency of description and discrimination for several matrices (Tomic et al., 2007; Murray \& Delahunty, 2000; Sulmont et al., 1999). However, they require extensive training before the panel can be used as reliable sensory instruments. Recently, several methods have been offered as alternatives which require no training and can be performed either by trained or untrained judges.

The ranking test has been used in consumer studies since the procedure is simple and the panel quite efficient (Hein et al., 2008; Lee et al., 2007; Lee \& O’Mahony, 2005; Liem et al., 2004; Villanueva et al., 2005; Kim \& O’Mahony, 1998; McEwan, 1999). Recently Pecore et al. (2014) used a trained panel with experience with the Spectrum Descriptive Analysis Method to compare the performance of a ranked scaling versus a traditional scaling to discriminate sets of grain-based foods. More significant differences were observed for the various samples within each product set with Ranked Scaling, suggesting the efficiency of the ranking procedure to discriminate samples.

In 2000, Sieffermann proposed Flash Profiling (FP) as a method to provide quick access to the relative sensory positioning of a set of products. The method is a combination of Free Choice Profiling (FCP) and a ranking procedure. The main specificity of FP is the comparative evaluation procedure of the whole product set (Delarue \& Sieffermann, 2004). Assessors simply rank the products' attributes focusing on perceived differences. Consequently, there was no need for a familiarization with the product set step anymore since panellists have simultaneous access to all samples and their differences. Flash profiling has been applied to describe different foods, including jams (Dairou \& Sieffermann, 2002), dairy products (Delarue \& Sieffermann, 2004), commercial apple and pear purees (Tarea et al., 2007), wines (Perrin et al., 2008), hot beverages (Moussaoui \& Varela, 2010), lemon iced teas (Veinand et al., 2011) and commercial soluble coffees (Kobayashi \& Benassi, 2012). A limitation of FP, being a comparative method, is the number of samples that can be assessed, which will depend on product category (Varela \& Ares, 2012).

Also in 2010, Rodrigue et al. (2000) firstly suggested combining QDA and ranking procedures. More recently, Richter et al., (2010) proposed the Ranking Descriptive Analysis (RDA) in which assessors first develop a consensual vocabulary, as in QDA, and, in the final step of the procedure, assessors are asked to rank samples for all selected terms. Richter et al. (2010)

${ }^{1}$ Departamento de Análises Bromatológicas, Faculdade de Farmácia, Universidade Federal da Bahia - UFBA, Salvador, BA, Brazil

${ }^{2}$ Departamento de Ciência e Tecnologia de Alimentos, Centro de Ciências Agrárias, Universidade Estadual de Londrina - UEL, Londrina, PR, Brazil

*Corresponding author: mmamede@ufba.br 
have concluded that the RDA method, using the pre-selection of assessors, attributes development and definition (qualitative aspect) and a ranking procedure for each attribute, allowed the discrimination of samples with an efficiency similar to well established descriptive methods (QDA and FCP). The authors also highlighted the facility of the procedure for ranking samples (ordinal scale), in comparison with the use of interval scales used by traditional descriptive techniques, allowing greater RDA panel consensus.

The two methods have in common the samples ranking procedure and the use of Generalized Procrustes Analysis (GPA) to analyze results. However, RDA data can also be analyzed by the Friedman Test that represents an advantage, considering the lack of GPA Programs.

Although not as fast as FP, RDA preserves the idea of using a consensual vocabulary and this facilitates data interpretation (Valentin et al., 2012). The terminology is FP's major concern: the interpretation of sensory characteristics is difficult due to the large number of terms, associated with the lack of definitions and evaluation procedures. Furthermore, FP terminology cannot be reused by another panel.

There is no information on the literature comparing RDA and FP methods. Considering the different approaches and the advantages of the two methods, the aim of this study was to evaluate the efficiency of Flash Profiling and Ranking Descriptive analysis and compare them using star fruit-flavored powdered drink as the study matrix.

\section{Materials and methods}

\subsection{Samples and preparation}

Commercial star fruit-flavored powdered drink - C light (Mondelèz, Brazil), available in the Londrina market, was used to prepare all beverages. The powdered drink contains sweeteners, pulp dehydrated of star fruit, acidulants, natural organic and inorganic dye and maltodextrin. Four samples with different characteristics were formulated in order to evaluate method efficiency.

The number of samples was defined considering that ranking procedures were limited to five or fewer samples (Pecore et al., 2014). Sample A was prepared by diluting the star fruit powdered-flavored drink in $500 \mathrm{~mL}$ water, as recommended on the package by the manufacturer. The other samples were prepared based on sample A with the addition of some components (sugar, acidifier, thickener or dye) with the purpose to modify sensory characteristics. The formulations were defined in preliminary tests in order to guarantee sensory differences between samples. Sample B was prepared by adding $35 \mathrm{~g}$ of commercial sugar (Açúcar da Barra, Brazil) and $1 \mathrm{~g}$ of citric acid (Mix LTDA, Brazil) to sample A. Sample C was prepared by adding $1 \mathrm{~g}$ of carboxymethylcelullose CMCs Cekol 99.5\% of purity (CP Kelco, USA) and $0.02 \mathrm{~g}$ of tartrazine (Mix LTDA, Brazil), and sample $\mathrm{D}$ by adding $15 \mathrm{~g}$ of sugar (Açúcar da Barra, Brazil) and $0.02 \mathrm{~g}$ tartrazine (Mix LTDA, Brazil) to sample A.

All samples were stored under refrigeration $\left(5 \pm 2{ }^{\circ} \mathrm{C}\right)$ before analysis.

\subsection{Physicochemical analyses}

The total soluble solid (TSS) was determined using a pocket refractometer Atago PAL-BX/RI (Tokyo, Japan) with automatic temperature compensation. The results were expressed as ${ }^{\circ} \mathrm{Brix}$.

The titratable acidity (TA) of the samples $(10 \mathrm{~mL})$ was carried out by titration with $\mathrm{NaOH} 0.1 \mathrm{M}$ and phenolphthalein (1\%) as indicator. Results were expressed as $\mathrm{g}$ of citric acid/100 mL.

The $\mathrm{pH}$ was determined using a pHmeter Hanna HI 3221 (USA).

Viscosity was determined using a Brookfild digital viscometer RVTDV-II (Harlow, United Kingdom) and a \#1 splindle at $100 \mathrm{rpm}$.

Turbidity was determined using a Perkin Elmer UV/VIS spectrophotometer (spectrometer Lambda 25 - Singapore) considering absorbance reading at $600 \mathrm{~nm}$ (AU) (Caleguer \& Benassi, 2007) .

For color analysis, samples were conditioned in cubet $(10 \mathrm{~mL})$, and the readings were made using a Minolta CR10 colorimeter (Tokyo, Japan), CIE D65 illuminant, and standard observer CIE $10^{\circ}$. Chroma $\left(\mathrm{C}^{\star}\right)$ and hue $\left(\mathrm{h}^{\circ}\right)$ values were obtained.

All analyzes were carried out in triplicate in a randomized experimental design. The average response showed a normal distribution and it was observed homogeneity of variances by Levene test. Results were evaluated by the one-way ANOVA and the Duncan test $(\mathrm{p}<0.05)$ using the Statistica version 7.0.

\subsection{Sensory analyses}

\section{Testing procedure, panel and glossary development}

Tests were conducted in the sensory analysis laboratory, under white light and in individual booths. Samples $(50 \mathrm{~mL})$ were served cold (taken immediately from the refrigerator) in $100 \mathrm{~mL}$ transparent plastic cups, coded with random-three digits. The presentation order was randomized for each assessor.

The panel was composed by assessors with different levels of experience with sensory analysis and with ages between 24 and 45 years. The number of assessors was set as 12 , as suggested by ISO 8587 (International Organization for Standardization, 2006) for product assessment on a descriptive criterion.

Assessors were recruited based on the frequency of consumption of fruit juices and the availability of time for analysis. Before analysis, assessors were instructed on the procedures describing the basic steps of the tests. A protocol was also presented with instructions to evaluate appearance attributes ("observe color, transparency, viscosity and the presence of particles"), aroma attributes ("sniff samples two or three times"), flavor attributes ("taste the drink and observe the flavors, rinsing the mouth between samples"), and other mouthfeel perceptions ("any mouthfeel except taste or flavor perceptions, rinsing the mouth between samples").

The assessors were previously informed about the products and testing procedures, as described in the project approved by National Research Ethics System (Project Project 057/2014 UEL, CAAE 17523914.1.0000.5231. 


\section{Flash Profiling (FP)}

One session was conducted for attributes development and sample analysis. The total session time was from $60 \mathrm{~min}$.

The four samples were presented simultaneously in order to obtain the highest possible number of attributes with regard to appearance, aroma, flavor and mouthfeel perceptions. Assessors were requested to record the similarities and differences between each sample.

After attributes development, an individual score sheet and a specific list of attributes definition were elaborated for each assessor. They were instructed that, if necessary, attributes that were identified during the analysis could be included.

Next, samples were present simultaneously for FP analysis. For each attribute, samples were ordered by increasing intensity,

Results were analyzed by the Generalized Procrustes Analysis (GPA), using the Senstools program Version 2.3.28 (OP \& P Product Research, 1998). Data were provided as 12 individual matrices (one per assessor) with four lines (samples) and a different number of columns ranging from 6 to 13, according to the number of attributes used by each assessor.

\section{Ranking Descriptive Analysis (RDA)}

As attribute development was already done for each judge, a panel session (60 min) was performed to choose attributes of consensus. The terms most frequently cited in the assessors' individual list from Flash profile were selected to compose the score sheet for the RDA panel. In the same session, the assessors defined the attributes and suggested qualitative references based on the samples and other commercial products. In a second session (individual), qualitative references were presented and checked by the panel (Table 1 ).

Samples evaluation by RDA was completed in one session in which, samples were ordered by increasing intensity for each attribute.

Results were evaluated by the Friedman test and using the table of the critical values of differences proposed by Christensen et al. (2006). Data was also evaluated by GPA, as described for FP. Data were provided as 12 individual matrices (one by judge) of four lines (samples) and 12 columns (attributes).

\section{Results}

\subsection{Physicochemical characterization}

Juice samples showed differences in many of the parameters assessed (Table 2). Sample B was characterized by higher SSA/AT ratio and the lowest $\mathrm{pH}$. Sample $\mathrm{C}$ was different from the other samples by its greater viscosity and saturation $\left(C^{\star}\right)$. Sample D presented higher $\mathrm{h}^{\circ}$ value, with a yellowish-green color. Sample C was characterized by low viscosity. Samples presented an average value of $0.63 \mathrm{UA}$ for turbidity, considered high turbidity once values of 0.31 a 1.0 UA have been described for orange-powdered flavored drinks (Caleguer et al., 2006).

\subsection{Sensory evaluation}

\section{Evaluation of assessors' performance: comparison between panel's behavior}

Each assessor's individual samples configuration for RDA and FP showed his/her ability to discriminate sample (data not showed), even with the use of different descriptors.

Table 1. Attributes, definitions and references used by RDA panels to describe the sensory properties of star fruit-flavored drink.

\begin{tabular}{|c|c|c|}
\hline Attribute & Definition & Qualitative reference \\
\hline Yellow color & Yellow color intensity. & Sample A with the addition of tartrazine $0.02 \mathrm{~g} / 100 \mathrm{~mL}$. \\
\hline Viscous appearance & $\begin{array}{l}\text { Perceived in the cup, viscosity related to the ability of the } \\
\text { liquid to flow. }\end{array}$ & $\begin{array}{l}\text { Sample A with addition of carboxymethylcellulose (CMC) } \\
(0.4 \mathrm{~g} / 100 \mathrm{~mL})\end{array}$ \\
\hline Transparency & Facility to see through the sample. & Sample A diluted in $2 \mathrm{~L}$ of water. \\
\hline Fruit aroma & Aroma characteristic of fruit juice. & $\begin{array}{l}\text { Sample A with added of } 3.3 \mathrm{~g} / 100 \mathrm{~mL} \text { of fruit salad-flavored } \\
\text { powdered - Tang }{ }^{\circledR} \text {. }\end{array}$ \\
\hline Citric aroma & Aroma of a citrus fruit juice such as orange and pineapple. & $\begin{array}{l}\text { Sample A with added of } 2.6 \mathrm{~g} / 100 \mathrm{~mL} \text { of orange-flavored } \\
\text { powdered - Fresh }^{\circledR} \text {. }\end{array}$ \\
\hline Sweet aroma & Aroma of a sweet fruit juice such as apple and mango. & $\begin{array}{l}\text { Sample A with added of } 3.3 \mathrm{~g} / 100 \mathrm{~mL} \text { of apple-flavored } \\
\text { powdered - Tang }{ }^{\circledR} \text {. }\end{array}$ \\
\hline Sweet flavor & Flavor associated with sugar. & Sample A with added of $0.6 \mathrm{~g} / 100 \mathrm{~mL}$ of sugar \\
\hline Acidity & Sensation associated to the sour taste & $\begin{array}{l}\text { Sample A with added of } 0.4 \mathrm{~g} / 100 \mathrm{~mL} \text { of citric acid (standard } \\
\text { food grade) }\end{array}$ \\
\hline Fruit flavor & Flavor characteristic of fruit juice. & $\begin{array}{l}\text { Sample A with added of } 0.2 \mathrm{~g} / 100 \mathrm{~mL} \text { of fruit salad -flavored } \\
\text { powdered - Tang }{ }^{\circledR} \text {. }\end{array}$ \\
\hline Viscosity & Associated with the sensation of recoating in the mouth & Sample A with added of CMC $(0.4 \mathrm{~g} / 100 \mathrm{~mL})$ \\
\hline Astringent & Lashing sensation in the mouth after swallowing the sample. & Integral cashew juice - Maguary $^{\circledR}$ \\
\hline Bitter aftertaste & Bitter aftertaste of sweeteners & Sample A $(250 \mathrm{~mL})$ with 30 drops of sweetener - Assugrin ${ }^{\circledR * *}$ \\
\hline
\end{tabular}


Residual variance analysis and the assessors' configuration (Figures 1 and 2) show a panel consensus for the two methods studied. In the two methods, it was not observed behaviour discrepancies among assessors and the maximum residual variance was $0.75 \%$, comparable to that described in other descriptive researches that applied ordering procedure as reported by Richter et al. (2010) for RDA.

The number of attributes of appearance, flavor, aroma, and mouthfeel perceptions raised by the Flash Profiling was
$5,8,13$, and 3 attributes, respectively. After a discussion over the attributes of consensus selection in the RDA, this number was reduced to 3 in each class of attributes (appearance, flavor, aroma, mouthfeel perceptions) (Table 1).

Consensus configurations show that the panel discriminated samples similarly for RDA and FP (Figure 3). Explained variability was high, from $80 \%$ to $72 \%$, respectively for FC and RDA. It is important to emphasize that samples variability were explained by a number of different attributes in each method studied.

Table 2. Physicochemical characteristics of samples ${ }^{1}$.

\begin{tabular}{|c|c|c|c|c|}
\hline \multirow{2}{*}{ Parameters } & \multicolumn{4}{|c|}{ Samples } \\
\hline & $\mathbf{A}$ & B & $\mathrm{C}$ & $\mathrm{D}$ \\
\hline Ratio $(\mathrm{TSS} / \mathrm{TA})^{2}$ & $1.60^{c} \pm 0.10$ & $10.53^{\mathrm{a}} \pm 0.25$ & $1.87^{c} \pm 0.23$ & $7.37^{\mathrm{b}} \pm 0.31$ \\
\hline $\mathrm{pH}$ & $2.93^{\mathrm{b}} \pm 0.06$ & $2.73^{c} \pm 0.06$ & $3.10^{\mathrm{a}} \pm 0.10$ & $2.97^{\mathrm{b}} \pm 0.06$ \\
\hline Viscosity (m.Pa.s) & $13.20^{\mathrm{d}} \pm 0.10$ & $15.40^{\mathrm{b}} \pm 0.10$ & $51.27^{\mathrm{a}} \pm 0.06$ & $14.17^{\mathrm{c}} \pm 0.58$ \\
\hline Turbidity (AU at $600 \mathrm{~nm}$ ) & $0.65^{\mathrm{a}} \pm 0.00$ & $0.60^{\mathrm{a}} \pm 0.00$ & $0.63^{\mathrm{a}} \pm 0.00$ & $0.64^{\mathrm{a}} \pm 0.01$ \\
\hline Chroma $\left(C^{\star}\right)$ & $6.2^{\mathrm{c}} \pm 0.1$ & $5.8^{\mathrm{d}} \pm 0.0$ & $9.7^{\mathrm{a}} \pm 0.0$ & $8.3^{b} \pm 0.0$ \\
\hline Hue $\left(\mathrm{h}^{\circ}\right)$ & $94.8^{\mathrm{c}} \pm 0.1$ & $93.1^{\mathrm{d}} \pm 0.3$ & $100.6^{\mathrm{b}} \pm 0.06$ & $101.6^{\mathrm{a}} \pm 0.1$ \\
\hline
\end{tabular}

${ }^{1}$ Mean (three analyses). Different letters in the same row indicate significant differences $(\mathrm{p}<0.05) ;{ }^{2}$ TSS (Total Soluble Solid) in ${ }^{\circ}$ Brix; TA (Titratable acidity) in (g citric acid/100 g).
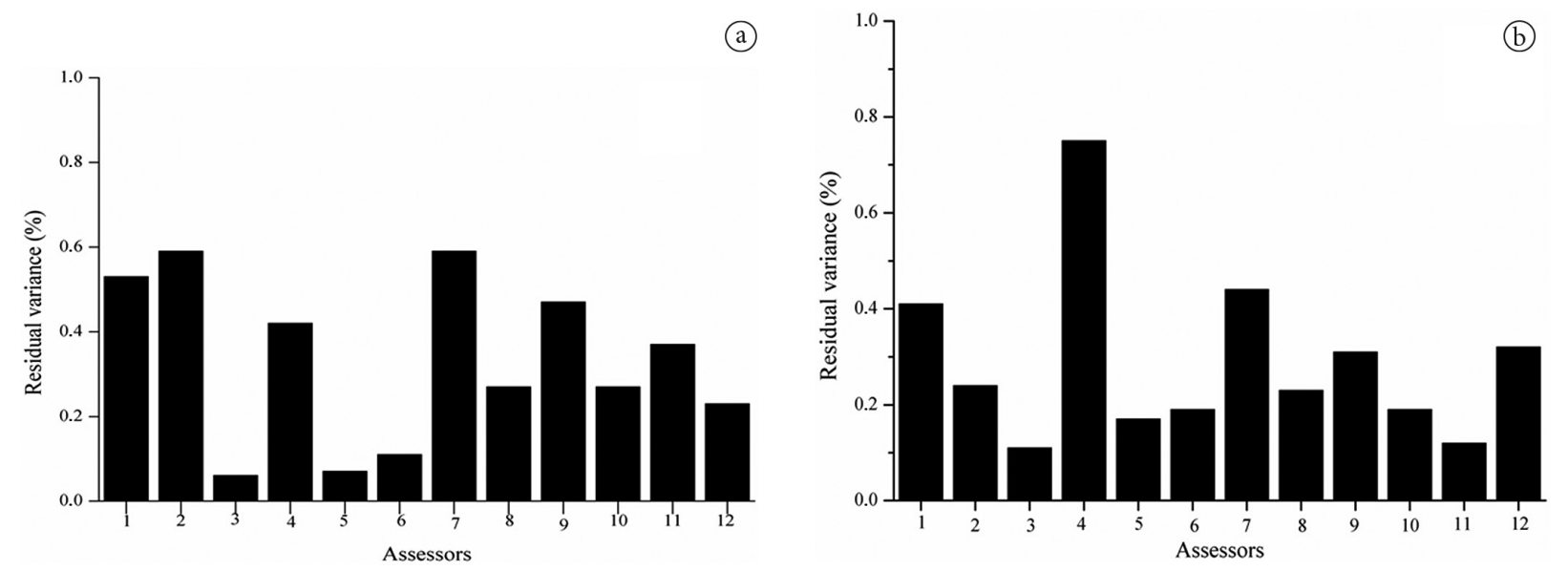

Figure 1. Residual variance (\%) associate with each assessor in FP (a) and RDA (b) panels.
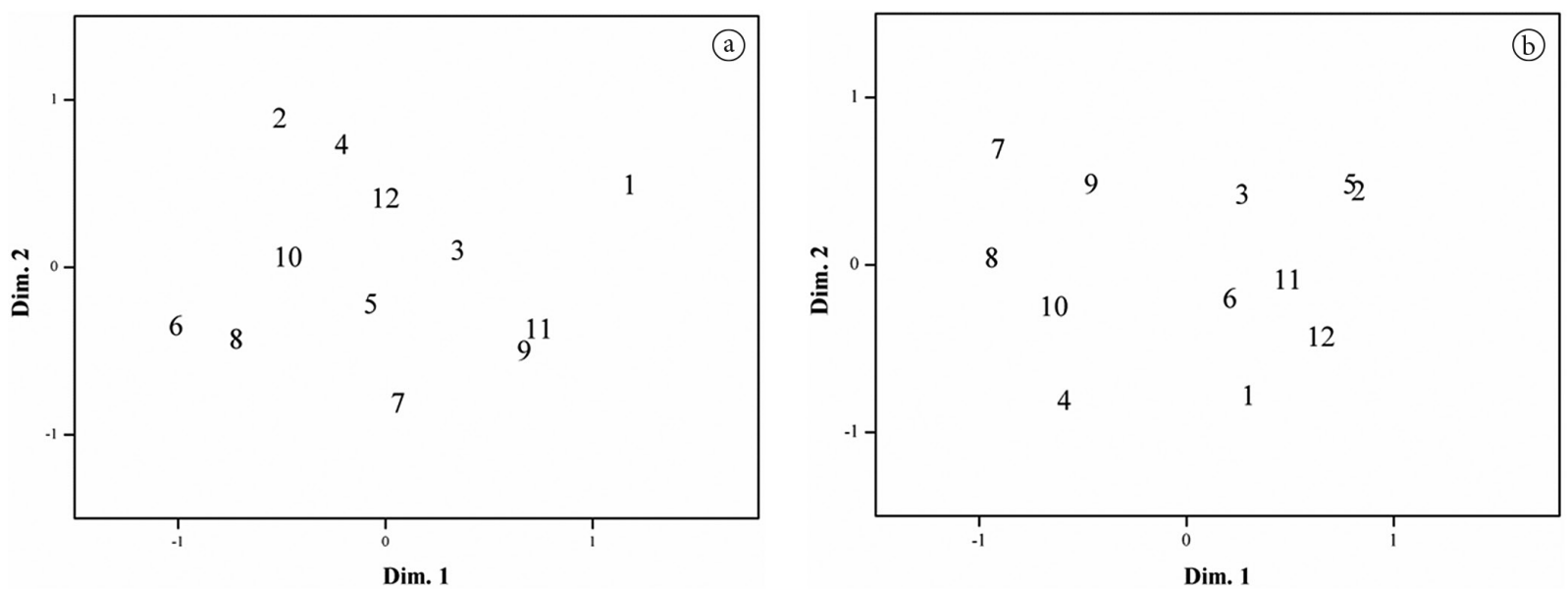

Figure 2. Graphic representation of the assessors' dispersion along the two first dimensions: general configuration of assessors in FP (a) and RDA (b). Numbers (1-12) indicates assessors. 

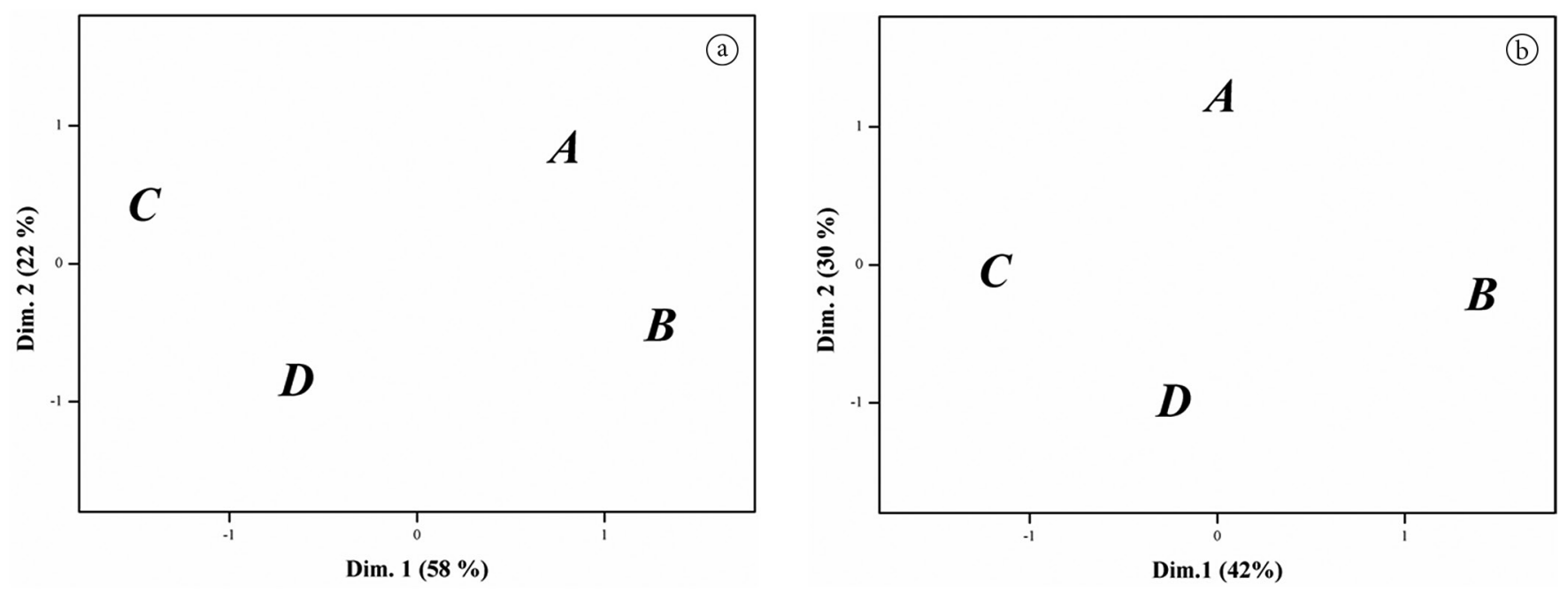

Figure 3. Two-dimensional consensus plot for star fruit-flavored drink (A, B, C and D) obtained by FP (a) and RDA (b).

\section{Samples evaluation}

A similar samples distribution in the two-dimensional space was observed when FP and RDA were compared, despite the additional stage adopted in the RDA, with the presentation of qualitative references and a consensus meeting among assessors.

For FP, the dimension 1 accounted for $58.1 \%$ of the variance among samples. It can be explained in the negative direction, by the yellow color (all assessors) and viscosity (in the mouth and/or in the cup (12 assessors) and, in the positive direction, by the watery characteristic (in appearance or in the mouth) ( 3 assessors), and also by the attributes of sweetness, sweet flavor, pineapple flavor and astringency. Dimension 2 explained 21.7\% of the variance among samples, and it was positively correlated with the attributes of sweetness/sweet flavor (7 assessors), fruity flavor (3 assessors) and aromas (citric, fruit, acid, pineapple and plum) (Figure $3 a$ and Table 3). Thus, samples C and D, located on the left side of the figure, were characterized by their highest yellow color intensity and viscosity (in the mouth and/or in the cup). Samples A and B, located on the right side of the figure, were characterized by the higher intensity of the attributes associated with a fruit (such as sweetness/sweet flavor, fruity flavor and citric taste/aroma).

For RDA, dimension 1 explained $42 \%$ of the variability among samples. It was explained, in the negative direction, with the yellow color, viscous appearance, and viscosity attributes, and positively correlated with the fruity flavor (6 assessors), astringent ( 4 assessors) and bitter aftertaste attributes ( 4 assessors). Dimension 2 (30\% of the variability) was characterized, in the negative direction, by sweet flavor and bitter aftertaste ( 6 assessors), and fruity flavor (8 assessors) attributes, and positively correlated with attributes of acidity ( 5 assessors), and sweet and fruity aroma (4 to 5 assessors) (Figure $3 \mathrm{~b}$ and Table 4). Sample B, located on the right side of the figure, was characterized by its fruity flavor, astringent and bitter aftertaste characteristics, while sample A, also located on the right side but closer to the central point, was characterized by its greater acidity and aroma (sweet and fruity) intensity. Samples C and D were located on the left side of the figure, and they were characterized by their viscous appearance, higher viscosity and the great intensity of sweet flavor and bitter aftertaste attributes.

Table 5 shows the results of the RDA by the attributes analysed. All samples presented a typical aromatic profile of fruit, but no difference $(\mathrm{p}<0.05)$ among samples was observed regarding fruit, citric and sweet aroma. Sample A was characterized as presenting higher acidity and less sweet flavor. Samples C and D showed the highest intensity of yellow color and high viscous appearance. Sample $\mathrm{C}$ also had the highest viscosity (recoating in the mouth). The bitter aftertaste was perceived in all samples, but the highest intensity was described for sample B, which was also characterized by its sweet flavor, acidity, fruity flavor and astringent characteristics.

\section{Discussion}

Panels demonstrated a very similar behavior, showing consensus and good discrimination (Figures 1 and 2), although samples were characterized by a different number of attributes by each method. Even with the familiarization stage with qualitative standards carried out by the RDA, it does not show better consensus among assessors when compared with FP. It was probably due to the easiness of the ranking procedure adopted by both methods. Panel consensus allowed good sample discrimination in both FP and RDA, and high percentages of variance were explained, $80 \%$ and $72 \%$, respectively (Figure 3 ).

In the FP, the number of attributes used consensually in sample characterization was small, around 7. In dimension 1, the greatest responsible for the discrimination, most attributes were related to appearance (yellow color, viscosity in the cup, and apparent viscosity) and some attributes related to fruit characteristics (star fruit aroma, astringent, sweetness, sweet flavor, and pineapple, acid and citric flavor) (Table 3).

In the RDA, the same attributes were used by all assessors, considering that some of them were already familiar to the panel since they were raised during the FP evaluation. In dimension 1, 
Table 3. Attributes better correlated $(R \geq 0.6)$ with the first two dimensions for each assessors on FP.

\begin{tabular}{|c|c|c|}
\hline Assessors & Dimension 1 & Dimension 2 \\
\hline 1 & $\begin{array}{l}\text { Yellow color }(-0.82) \text {; floral aroma }(-0.88) \text {; star fruit flavor }(-0.82) \text {; } \\
\text { astringent }(0.82) \text {. }\end{array}$ & Citric aroma (0.74); sweetness $(0.86)$. \\
\hline 2 & $\begin{array}{l}\text { Yellow color }(-0.82) \text {; viscosity in the cup }(-0.99) \text {; star fruit flavor } \\
(-0.88) \text {; sweetness }(0.99) \text {; viscosity }(-0.99)\end{array}$ & \\
\hline 3 & $\begin{array}{l}\text { Yellow color }(-0.99) \text {; sweet aroma }(-0.82) \text {; acid flavor }(0.99) \text {; } \\
\text { sweetish flavor }(0.99) \text {; watery }(0.99) \text {. }\end{array}$ & Fruit aroma (0.99); fruit flavor (0.99). \\
\hline 4 & $\begin{array}{l}\text { Yellow color }(-0.82) \text {; pineapple flavor }(0.99) \text {; watery texture }(0.99) \text {; } \\
\text { sweet aroma }(-0.88) \text {; astringent taste }(0.88) \text {. }\end{array}$ & \\
\hline 5 & $\begin{array}{l}\text { Yellow color }(-0.82) \text {; transparency }(0.72) \text {; viscosity in the cup } \\
(-0.99) \text {; acid aroma }(0.82) \text {; viscosity }(-0.88) \text {; suspended particles } \\
(-0.88) \text {. }\end{array}$ & Sweet aroma $(-0.85)$; fruit flavor $(0.72)$; sweet flavor $(0.72)$ \\
\hline 6 & $\begin{array}{l}\text { Yellow color }(-0.72) \text {; viscosity in the cup }(-0.99) \text {; turbidity }(0.99) \text {; } \\
\text { star fruit aroma }(-0.99) \text {; acidity }(0.99) \text {; viscosity }(-0.88) \text {. }\end{array}$ & Sweetness (0.72) \\
\hline 7 & $\begin{array}{l}\text { Yellow color }(-0.72) \text {; astringent }(0.88) \text {; viscosity }(-0.99) \text {; watery } \\
\text { appearance }(0.72) \text {; }\end{array}$ & Sweet aroma (0.85); sweet flavor (0.85). \\
\hline 9 & Yellow color $(-0.99)$; transparency $(0.72)$ & Sweet flavor (0.72); acid flavor (0.72); viscosity in mouth (-0.72). \\
\hline 10 & $\begin{array}{l}\text { Yellow color }(-0.99) \text {; viscosity }(-0.99) \text {; acidity }(0.99) \text {; viscosity in } \\
\text { mouth }(-0.99) \text {. }\end{array}$ & Fruit flavor (0.72). \\
\hline 11 & Yellow color (-0.99); turbidity $(0.72)$; viscosity in mouth $(-0.99)$. & $\begin{array}{l}\text { Apparent viscosity }(-0.85) \text {; sweetness }(0.86) \text {; acidity }(0.72) \text {; } \\
\text { metallic taste }(0.72) \text {. }\end{array}$ \\
\hline 12 & $\begin{array}{l}\text { Yellow color }(-0.82) \text {; transparency }(-0.88) \text {; viscosity }(-0.99) \text {; } \\
\text { brightness }(-0.88) \text {; blackberry aroma }(-0.82) \text {; raspberry flavor } \\
(-0.82) \text {; blackcurrant flavor }(-0.88) \text {; sweet flavor }(0.99) \text {; citric flavor } \\
(0.88) \text {; viscosity in mouth }(-0.88) \text {. }\end{array}$ & Pineapple aroma (0.99); plum aroma $(0.85)$ \\
\hline
\end{tabular}

Table 4. Attributes better correlated $(\mathrm{R} \geq 0.6)$ with the first two dimensions for each assessors on RDA.

\begin{tabular}{|c|c|c|}
\hline Assessors & Dimension 1 & Dimension 2 \\
\hline 1 & $\begin{array}{l}\text { Viscous appearance (-0.97); transparency }(-0.91) \text {; fruit flavor } \\
(0.74) \text {. }\end{array}$ & $\begin{array}{l}\text { Yellow color }(-0.64) \text {; fruit aroma }(0.91) \text {; sweet aroma }(0.64) \text {; sweet } \\
\text { flavor }(-0.74) \text {; viscosity }(-0.64) \text {; bitter aftertaste }(-0.96) \text {. }\end{array}$ \\
\hline 2 & Yellow color $(-0.74)$; transparency $(0.97)$ & $\begin{array}{l}\text { Fruit aroma }(0.6) \text {; citric aroma }(0.74) \text {; acidity }(0.91) \text {; viscosity } \\
(-0.6) \text {. }\end{array}$ \\
\hline 3 & $\begin{array}{l}\text { Yellow color }(-0.74) \text {; transparency }(-0.74) \text {; sweet aroma }(-0.74) \text {; } \\
\text { acidity }(0.91) \text {; fruit flavor }(0.97) \text {; bitter aftertaste }(0.91) .\end{array}$ & Fruit aroma $(0.74)$; citric aroma $(-0.6)$. \\
\hline 4 & $\begin{array}{l}\text { Yellow color }(-0.74) \text {; viscous appearance }(-0.97) \text {; transparency } \\
(0.74) \text {; fruit aroma }(-0.74) \text {; sweet aroma }(-0.74) \text {; fruit flavor }(-0.74) \text {; } \\
\text { viscosity }(-0.74) \text {. }\end{array}$ & $\begin{array}{l}\text { Citric aroma }(-0.91) \text {; sweet flavor }(-0.74) \text {; acidity }(0.91) \text {; astringent } \\
(0.64) \text {; bitter aftertaste }(-0.74) \text {. }\end{array}$ \\
\hline 5 & $\begin{array}{l}\text { Yellow color }(-0.74) \text {; fruit aroma }(0.91) \text {; fruit flavor }(0.91) \text {; bitter } \\
\text { aftertaste }(0.91) \text {. }\end{array}$ & Sweet aroma (0.6); sweet flavor $(-0.6)$. \\
\hline 6 & $\begin{array}{l}\text { Citric aroma (-0.97); acidity (0.97); fruit flavor }(0.91) \text {; astringent } \\
(0.91) \text {; bitter aftertaste }(0.91) \text {. }\end{array}$ & $\begin{array}{l}\text { Yellow color }(-0.91) \text {; viscous appearance }(-0.64) \text {; fruit aroma } \\
(-0.64) \text {; sweet flavor }(-0.74) \text {. }\end{array}$ \\
\hline 7 & $\begin{array}{l}\text { Yellow color }(-0.74) \text {; viscous appearance }(-0.97) \text {; transparency } \\
(-0.74) \text {; fruit flavor }(0.91) \text {; viscosity }(-0.91) \text {; astringent }(0.91) \text {. }\end{array}$ & $\begin{array}{l}\text { Fruit aroma }(-0.74) \text {; citric aroma }(0.74) \text {; sweet aroma }(-0.74) \text {; sweet } \\
\text { flavor }(-0.96) \text {; acidity }(0.74) \text {; bitter aftertaste }(-0.96) \text {. }\end{array}$ \\
\hline 9 & $\begin{array}{l}\text { Yellow color }(-0.91) \text {; sweet aroma }(0.74) \text {; sweet flavor }(0.97) \text {; } \\
\text { acidity }(0.91) \text {; fruit flavor }(0.91) \text {. }\end{array}$ & $\begin{array}{l}\text { Viscous appearance }(-0.74) \text {; fruit aroma }(-0.74) \text {; citric aroma } \\
(-0.74) \text {; viscosity }(-0.64) \text {; astringent }(-0.74) \text {; bitter aftertaste }(-0.74) \text {. }\end{array}$ \\
\hline 10 & $\begin{array}{l}\text { Yellow color }(-0.74) \text {; viscous appearance }(-0.74) \text {; transparency } \\
(-0.74) \text {; sweet aroma }(-0.91) \text {; acidity }(0.97) \text {; viscosity }(-0.91) ; \\
\text { astringent }(0.97) \text {. }\end{array}$ & $\begin{array}{l}\text { Fruit aroma }(0.64) \text {; citric aroma }(-0.6) \text {; sweet flavor }(-0.74) \text {; fruit } \\
\text { flavor }(0.91) \text {; bitter aftertaste }(0.96) \text {. }\end{array}$ \\
\hline 11 & $\begin{array}{l}\text { Yellow color }(-0.74) \text {; viscous appearance }(-0.97) \text {; fruit aroma } \\
(-0.91) \text {; citric aroma }(0.74) \text {. }\end{array}$ & $\begin{array}{l}\text { Transparency }(-0.6) \text {; sweet flavor }(-0.74) \text {; acidity }(0.64) \text {; astringent } \\
(0.64) \text {; bitter aftertaste }(-0.6) \text {. }\end{array}$ \\
\hline 12 & $\begin{array}{l}\text { Fruit aroma }(-0.97) \text {; citric aroma }(0.64) \text {; sweet flavor }(0.91) \text {; } \\
\text { viscosity }(-0.97) \text {; bitter aftertaste }(0.91) \text {. }\end{array}$ & Yellow color $(-0.64)$; sweet aroma $(0.74)$; acidity $(0.64)$. \\
\hline
\end{tabular}


Table 5. Characterization of samples by RDA ${ }^{\mathrm{A}, \mathrm{B}}$.

\begin{tabular}{|c|c|c|c|c|}
\hline \multirow{2}{*}{ Attributes } & \multicolumn{4}{|c|}{ Samples } \\
\hline & $\mathrm{A}$ & $\mathrm{B}$ & $\mathrm{C}$ & $\mathrm{D}$ \\
\hline Yellow color & $21^{\mathrm{b}}$ & $15^{\mathrm{b}}$ & $38^{\mathrm{a}}$ & $46^{\mathrm{a}}$ \\
\hline Viscous appearance & $21^{\mathrm{b}}$ & $24^{\mathrm{b}}$ & $45^{\mathrm{a}}$ & $30^{\mathrm{b}}$ \\
\hline Fruit aroma & $33^{\mathrm{a}}$ & $27^{\mathrm{a}}$ & $34^{\mathrm{a}}$ & $26^{\mathrm{a}}$ \\
\hline Citric aroma & $35^{\mathrm{a}}$ & $28^{\mathrm{a}}$ & $25^{\mathrm{a}}$ & $32^{\mathrm{a}}$ \\
\hline Acidity & $39^{a}$ & $38^{\mathrm{a}}$ & $18^{\mathrm{b}}$ & $25^{\mathrm{b}}$ \\
\hline Fruit flavor & $32^{\mathrm{a}}$ & $38^{\mathrm{a}}$ & $20^{\mathrm{b}}$ & $30^{\mathrm{ab}}$ \\
\hline Viscosity & $21^{\mathrm{b}}$ & $23^{\mathrm{b}}$ & $47^{\mathrm{a}}$ & $29^{\mathrm{b}}$ \\
\hline Astringent & $34^{\mathrm{b}}$ & $40^{\mathrm{a}}$ & $18^{\mathrm{b}}$ & $28^{\mathrm{b}}$ \\
\hline Bitter aftertaste & $20^{\mathrm{b}}$ & $43^{\mathrm{a}}$ & $21^{\mathrm{b}}$ & $36^{\mathrm{ab}}$ \\
\hline
\end{tabular}

${ }^{A}$ Rank sums values of 12 assessors; ${ }^{B}$ Different letters in the same line indicate significant differences $(\mathrm{p}<0.05 ; \mathrm{MDS}=12$ ) according to Christensen et al. (2006).

there was great similarity with the description obtained by FP, with great contribution of the appearance attributes (yellow color, viscous appearance and viscosity), but still with the contribution of other attributes such as fruity flavor. It is important to emphasize that astringent and bitter aftertaste attributes were also used in sample description and discrimination (Table 4) and they had not been highlighted during the FP. By comparing the RDA results (Table 5) it is verified that samples A and B differed from $\mathrm{C}$ and $\mathrm{D}$ considering the yellow color and that sample $\mathrm{C}$ differed from all samples in regards to viscous appearance $(\mathrm{p}<0.05)$.

In dimension 2, discrimination was attributed mainly to sweet flavor on the FP evaluation. In RDA, besides the sweet flavor, the bitter aftertaste attribute was also used in sample description and discrimination (D 2). These attributes were the most important for the characterization of samples B and D, and in agreement with the data presented in Table 5.

The consistent use of the bitter aftertaste attribute by the panel was important for the better discrimination of samples $\mathrm{A}$ and $\mathrm{B}$ observed during the RDA (Figure 3, Tables 4 and 5) when compared to the description obtained by FP (Figure 3).

Aroma attributes, which showed correlation with dimension 2 for the two methods, were not relevant for discrimination (Tables 3 and 4 ). The result is consistent with the aroma similarity described for samples in the RDA (Table 5).

Comparison between the description obtained by the RDA (Table 5) with the composition and physicochemical characterization of the samples shows the consistency of the sensory panel even when using only qualitative training. Sample $\mathrm{C}$, to which gum was added, was described as the more viscous (Table 5) and presented higher viscosity (51.25 m.Pa.s) (Table 2). Sample B, which had greater addition of sugar, showed greater SSA/AT ratio (10.53) (Table 2) and was described as more sweet than samples A and C (Table 5). Sample C showed the highest value for $C^{\star}$ (9.7) and sample $D$ highest value for hue (101.57) (Table 2), being described as those with the higher yellow color intensity (Table 5) in agreement with the addition of tartrazine dye in the two formulations.
Pecore et al. (2014) reported that a ranking procedure allows an accurate measurement of intensity (studied in model sucrose and salt solutions) and pointed out that ranking methods can still be very efficient to correlate with instrumental data. Richter et al. (2010) described a good correlation between instrumental data and sensory description by RDA. Kobayashi \& Benassi (2012) also reported on correlation between physicochemical characterization and the sensory characteristics of commercial soluble coffees using FP.

Considering the matrix used, there were no difference in samples discrimination by consensus configuration in the two methods, although the qualitative training stage proposed by $\mathrm{RDA}$. However, the importance of the bitter aftertaste attribute to samples differentiation was observed $(\mathrm{p}<0.05)$, and the attribute was consistently used by the panel only after the training on RDA.

RDA inherent advantages should also be considered such as the greater facility to analyze data using Friedman test (Table 6) which allow for the comparison of attributes (at the selected level of significance) and which is available in many statistical software. All results were analysed by GPA; however, the Friedman test only can be used for the RDA. This represents an advantage in relation to the FP considering the lack of availability of GPA programs.

A comparison of the applicability of sensory methods (number of assessors, amount of sample and time required) can be observed in Table 6. For the same number of assessors, sample amount are slightly differentiated between the two methods. Data, however, do not consider the additional in the definition and the preparation of qualitative reference samples for RDA. The FP was the fastest method (one session), since some stages used in the RDA were absent from de FP (definition of attributes and presentation of qualitative references), implying an economy of time for the RDA. It is important to highlight, however, that the less time spent in FP evaluation is associated with the assessor. In relation to the time spent by the researcher, it was almost the same for both methods. Summarizing, it is estimated that the application of the methods would have similar cost. 
Table 6. Comparison of the requirements for FP and RDA.

\begin{tabular}{|c|c|c|c|}
\hline & & FP & $\mathrm{RDA}$ \\
\hline \multirow[t]{4}{*}{ Stages } & Attributes development & One individual session (45 $\mathrm{min})$ & One individual session (45 min) \\
\hline & Definition of attributes & & One session with the panel (60 min) \\
\hline & Presentation of qualitative references & & One session (15 $\mathrm{min}$ for each assessor) \\
\hline & Samples evaluation & $\star(15 \mathrm{~min})$ & One individual session (15 min) \\
\hline \multicolumn{2}{|c|}{ Time $(\mathrm{min}) /$ session for assessors ${ }^{* *}$} & $60 \mathrm{~min} /$ one individual session & $135 \mathrm{~min} /$ four sessions \\
\hline \multicolumn{2}{|c|}{ Time $(\mathrm{min}) /$ session for researcher $* \star$} & $820 \mathrm{~min} /$ one session for each assessor & $880 \mathrm{~min} /$ four sessions + references preparation ${ }^{\star \star \star}$ \\
\hline \multicolumn{2}{|c|}{ Number of assessors } & 12 & 12 \\
\hline \multicolumn{2}{|c|}{ Amount of sample } & $4800 \mathrm{~mL}$ & $4800 \mathrm{~mL}+$ references $^{* * *}$ \\
\hline \multicolumn{2}{|c|}{ Analysis of results } & GPA & GPA and Friedman \\
\hline
\end{tabular}

* The same session used for attributes development; ${ }^{* *}$ Samples preparation not considered; ${ }^{* *}$ Qualitative references.

\section{Conclusion}

A comparison between FP and RDA, here exemplified with a star fruit-flavored powdered drink matrix, showed that the two methods were efficient, allowed similar samples discrimination and were in agreement with the physicochemical characterization of the samples. FP application was simpler and faster, mainly in regards to time spent by the assessor, but the RDA method provided a more comprehensive description of samples with the use of a greater number of attributes.

\section{Acknowledgements}

We thank CP Kelco (Brazil) for donation of the carboxymethylcelullose CMCs Cekol. This work was supported by "Fundação de Amparo a Pesquisa do Estado da Bahia" (BOL3185/2013).

\section{References}

Brandt, M. A., Skinner, E. Z., \& Coleman, J. A. (1963). The texture profile method. Journal of Food Science, 28(4), 404-409. http:// dx.doi.org/10.1111/j.1365-2621.1963.tb00218.x.

Cairncross, S. E., \& Sjöstrom, L. B. (1950). Flavor profiles: a new approach to flavor problems. Food Technology, 4(8), 308-311.

Caleguer, V. F., \& Benassi, M. T. (2007). Effect of adding pulp, carboxymethyl cellulose and arabic gum to sensory characteristics and acceptance of powdered orange-flavored refreshments. Food Science and Technology, 27(2), 270-277. http://dx.doi.org/10.1590/ S0101-20612007000200010.

Caleguer, V. F., Toffoli, E. C., \& Benassi, M. T. (2006). Avaliação da aceitação de preparados sólidos comerciais para refresco sabor laranja e correlação com parâmetros físico-químicos. Semina. Ciências Agrárias, 27(4), 587-598.

Christensen, Z. T., Ogden, L. V., Dunn, M. L., \& Eggett, D. L. (2006). Multiple comparison procedures for analysis of ranked data. Journal of Food Science, 71(2), S132-S143. http://dx.doi. org/10.1111/j.1365-2621.2006.tb08916.x.

Dairou, V., \& Sieffermann, J. M. (2002). A comparison of 14 jams characterized by onventional profile and a quick original method, the flash profile. Journal of Food Science, 67(2), 826-834. http:// dx.doi.org/10.1111/j.1365-2621.2002.tb10685.x.

Delarue, J., \& Sieffermann, J. M. (2004). Sensory mapping using flash profile. Comparison with a conventional descriptive method for the evaluation of the flavour of fruit dairy products. Food Quality and Preference, 15(4), 383-392. http://dx.doi.org/10.1016/S09503293(03)00085-5.

Hein, K. A., Jaeger, S. R., Carr, T. B., \& Delahunty, C. M. (2008), Comparison of five common acceptance and preference methods. Food Quality and Preference, 19(7), 651-661. http://dx.doi.org/10.1016/j. foodqual.2008.06.001.

International Organization for Standardization - ISO. (2006). ISO 8587: Sensory analysis - Methodology - Ranking. Geneva: ISO.

Kim, K., \& O’Mahony, M. A. (1998). New approach to category scales of intensity: Traditional vs. rank-rating. Journal of Sensory Studies, 13(3), 241-249. http://dx.doi.org/10.1111/j.1745-459X.1998.tb00086.x.

Kobayashi, M. L., \& Benassi, M. T. (2012). Sensory characterization of commercial soluble coffees by Flash Profile. Semina: Ciências Agrárias, 33(2), 3081-3092.

Lawless, H. T., \& Heymann, H. (2010) Sensory evaluation of food: principles and practices (p. 850). New York: Springer.

Lee, H. S., \& O’Mahony, M. A. (2005). Sensory evaluation and marketing: measurement of a consumer concept. Food Quality and Preference, 16(3), 227-235. http://dx.doi.org/10.1016/j.foodqual.2004.04.013.

Lee, H. S., Hout, D., \& O’Mahony, M. (2007). Sensory difference tests for margarine: a comparison of R-indices derived from ranking and A-Not A methods considering response bias and cognitive strategies. Food Quality and Preference, 18(4), 675-680. http://dx.doi. org/10.1016/j.foodqual.2006.10.003.

Liem, D. G., Mars, M., \& Graaf, C. (2004). Consistency of sensory testing with 4-and 5-year-old children. Food Quality and Preference, 15(4), 541-548. http://dx.doi.org/10.1016/j.foodqual.2003.11.006.

McEwan, J. A. (1999). Comparison of sensory panels: a ring trial. Food Quality and Preference, 10(3), 161-171. http://dx.doi.org/10.1016/ S0950-3293(99)00013-0.

Moussaoui, K. A., \& Varela, P. (2010). Exploring consumer product profiling techniques and their linkage to a quantitative descriptive analysis. Food Quality and Preference, 21(8), 1088-1099. http:// dx.doi.org/10.1016/j.foodqual.2010.09.005.

Munoz, A. M., \& Civille, G. V. (1992). The spectrum descriptive analysis method. In R. C. Hootman (Ed.), Manual on descriptive analysis testing (ASTM Manual Series MNL, Vol. 13, pp. 22-34). West Conshohocken: ASTM International.

Murray, J. M., \& Delahunty, C. M. (2000). Selection of standards to reference terms in a Cheddar cheese flavor language. Journal of Sensory Studies, 15(2), 179-199. http://dx.doi.org/10.1111/j.1745459X.2000.tb00264.x.

OP \& P Product Research. (1998). Senstools version 2.3. Utrecht: OP \& P Product Research. 
Pecore, S., Kamerud, J. \& Holschuh, N. (2014). Ranked-scaling: a new descriptive panel approach for rating small differences when using anchored intensity scales. Food Quality Preference, 40(Part B), 376-380.

Perrin, L., Symoneaux, R., Maître, I., Asselin, C., Jourjon, F., \& Pagès, J. (2008). Comparison of three sensory methods for use with the Napping ${ }^{\circledR}$ procedure: Case of ten wines from Loire Valley. Food Quality and Preference, 19(1), 1-11. http://dx.doi.org/10.1016/j. foodqual.2007.06.005.

Richter, V. B., Almeida, T. C. A., Prudencio, S. H., \& Benassi, M. T. (2010). Proposing a ranking descriptive sensory method. Food Quality and Preference, 21(6), 611-620. http://dx.doi.org/10.1016/j. foodqual.2010.03.011.

Rodrigue, N., Guillet, M., Fortin, J., \& Martin, J. F. (2000). Comparing information obtained from ranking and descriptive tests of four sweet corn products. Food Quality and Preference, 11(1-2), 47-54. http://dx.doi.org/10.1016/S0950-3293(99)00063-4.

Stampanoni, C. R. (1993). The quantitative flavour profiling technique. Perfumer and Flavorist, 18, 19-24.

Stone, H., Sidel, J. L., Oliver, S., Woolsey, A., \& Singleton, R. C. (1974). Sensory evaluation by quantitative descriptive analysis. Food Technology, 28(11), 24-34.

Sulmont, C., Lesschaeve, I., Sauvageot, F., \& Issanchou, S. (1999). Comparative training procedures to learn odor descriptors: effects on profiling performance. Journal of Sensory Studies, 14(4), 467-490. http://dx.doi.org/10.1111/j.1745-459X.1999.tb00128.x.
Tarea, S., Cuvelier, G., \& Sieffermann, J. M. (2007). Sensory evaluation of the texture of 49 commercial apple and pear purees. Journal of Food Quality, 30(6), 1121-1131. http://dx.doi.org/10.1111/j.17454557.2007.00174.x.

Tomic, O., Nilsen, A., Martens, M., \& Naes, T. (2007). Visualization of sensory profiling data for performance monitoring. LWT. Food Science and Technology, 40(2), 262-269. http://dx.doi.org/10.1016/j. lwt.2005.09.014.

Valentin, D., Chollet, S., Lelie'vre, M., \& Abdi, H. (2012). Quick and dirty but still pretty good: a review of new descriptive methods in food science. International Journal of Food Science \& Technology, 47(8), 1563-1578. http://dx.doi.org/10.1111/j.1365-2621.2012.03022.x.

Varela, P. \& Ares, G. (2012). Sensory profiling, the blurred line between sensory and consumer science. A review of novel methods for product characterization. Food Research International, 48(2), 893-908. http:// dx.doi.org/ 10.1016/j.foodres.2012.06.037.

Veinand, B., Godefroy, C., Adam, C., \& Delarue, J. (2011). Highlight of important product characteristics for consumers. Comparison of three sensory descriptive methods performed by consumers. Food Quality and Preference, 22(5), 474-485. http://dx.doi.org/10.1016/j. foodqual.2011.02.011.

Villanueva, N. D. M., Petenate, A. J., \& Silva, M. A. A. P. (2005). Performance of the hybrid hedonic scale as compared to the traditional hedonic, self-adjusting and ranking scales. Food Quality and Preference, 16(8), 691-703. http://dx.doi.org/10.1016/j.foodqual.2005.03.013. 